\title{
Commentary: More than just the tube
}

\author{
Alexander J. Gregory, MD, FRCPC
}

\footnotetext{
From the Department of Anesthesiology, Perioperative, and Pain Medicine, Cumming School of Medicine, University of Calgary, Calgary, Alberta, Canada; and Libin Cardiovascular Institute of Alberta, Calgary, Alberta, Canada.

Disclosures: Author has nothing to disclose with regard to commercial support.

Received for publication May 30, 2019; accepted for publication May 31, 2019; available ahead of print July 18 , 2019.

Address for reprints: Alexander J. Gregory, MD, FRCPC, Department of Anesthesiology, Perioperative, and Pain Medicine, University of Calgary, Foothills Medical Center, Main Building, Rm C229, 1405 29th St, NW, Calgary, Alberta, Canada T2N 2T9 (E-mail: alex.gregory@albertahealthservices.ca).

J Thorac Cardiovasc Surg 2020;159:1403-4

$0022-5223 / \$ 36.00$

Crown Copyright (C) 2019 Published by Elsevier Inc. on behalf of The American Association for Thoracic Surgery https://doi.org/10.1016/j.jtcvs.2019.05.078
}

Interest in enhanced recovery programs (ERPs) has grown rapidly within the cardiac surgery community, demonstrated by several new publications on North American results and a recent evidence-based consensus document. ${ }^{1,2}$ Grant and colleagues ${ }^{3}$ show that compliance with a multi-faceted intraoperative protocol resulted in improved extubation metrics as well as in reduced hospital length of stay (LOS). The link between intraoperative extubation and LOS may provide a glimpse into the potential background mechanisms that are the foundation of enhanced recovery. Perhapsthere is a deeper meaning in these results - we must not focus solely on the tube.

The high-compliance group had a median reduction in intubation time of 3 hours. If patients subsequently continued down their recovery pathway in an unaltered manner, we should expect the same 3-hour reduction in hospital LOS, rather than the reported 20 hours. How can we explain those additional hours? Certainly, there could be health care provider bias that is not captured, despite the rigorous propensity matching performed by the authors. But there are also plausible alternative explanations that deserve consideration.

Incremental marginal gains revealing themselves downstream is a pillar of the ERP movement. ${ }^{4}$ Individual small interventions may not be impactful on their own, but when combined and applied consistently may add up to results greater than the parts. The interoperative protocol applied by Grant and colleagues ${ }^{3}$ included interventions aimed toward improved analgesia, opioid use reduction, and lung protection. Although they did not report any outcomes specific to those aims, based on existing literature it is reasonable to hypothesize that improvements would have been found had they been measured. The detrimental physiologic effects of pain and atelectasis, in addition to the various opioid-related side effects, have been well described. Certainly, optimizing those clinical parameters facilitated the successful intraoperative extubation achieved in the high-compliance group. However, there may have counterparts.

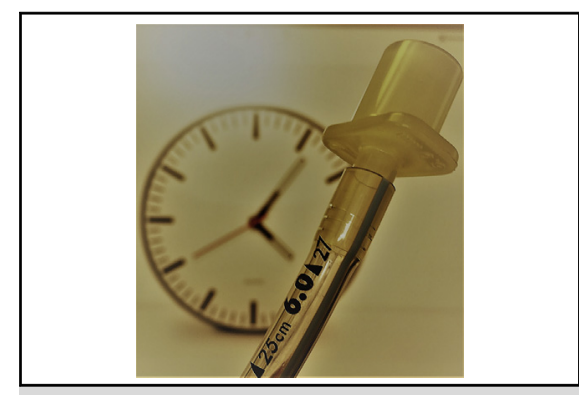

Can removing an endotracheal tube 3 hours earlier save a day in hospital?

\section{Central Message}

Optimizing for extubation may benefit patients beyond simply removing the endotracheal tube. Understanding mechanisms behind cumulative downstream effects are important to enhanced recovery programs.

See Article page 1393.

been unmeasured improvements in postoperative cognition, gut function and nutrition, pulmonary rehabilitation, and mobilization compared with their low-compliance

ERPs can seem like an assembly line, with care bundles applied in a predictable and consistent manner. But, in fact, they are still prinicipally delivered by people and thus are subject to the effects of human factors. The fast-paced, chaotic nature of medicine lends itself to health care providers relying on the status quo. The effect of organizational culture and structure on extubation was demonstrated by the fast-track experts from Leipzig, Germany. ${ }^{5}$ Probst and colleagues ${ }^{5}$ randomized identical groups of fast-track-eligible patients to their usual location (a specialized nonintensive care postanesthesia care unit) or intensive care unit. Despite no patient-specific reasons that they could not be extubated at the same rates, the postanesthesia care unit group was extubated significantly sooner (90 minutes vs 478 minutes) as a result of their different location-culture matters. ${ }^{5}$

Extubation is an important quality-of-care metric. Grant and colleagues ${ }^{3}$ should be congratulated on developing an intraoperative protocol that, when adhered to, results in successful intraoperative extubation. Implementation scientists recommend that we rigorously evaluate our outcomes to determine their true nature, thus increasing the knowledge gained. ${ }^{6}$ If we look beyond the actions directly in front of us, like pulling a tube, we may find that our current 
outcomes are also useful for evaluation of indirectly related process measures, human factors, and the deeper understanding of gains from cardiac ERPs, as opposed to being simply the root cause itself.

\section{References}

1. Engelman DT, Ben Ali W, Williams JB, Perrault LP, Reddy VS, Arora RC, et al. Guidelines for perioperative care in cardiac surgery: enhanced recovery after surgery society recommendations. JAMA Surg. May 4, 2019 [Epub ahead of print]. 2. Williams JB, McConnell G, Allender JE, Woltz P, Kane K, Smith PK, et al. One-year results from the first US-based enhanced recovery after cardiac surgery (ERAS Cardiac) program. J Thorac Cardiovasc Surg. 2019;157: 1881-8.

3. Grant M, Isada T, Ruzankin P, Whitman G, Lawton JS, Dodd-o J, et al. Results from an enhanced recovery program for cardiac surgery. J Thorac Cardiovasc Surg. 2020;159:1393-402.e7.

4. Durrand JW, Batterham AM, Danjoux GR. Pre-habilitation (i): aggregation of marginal gains. Anaesthesia. 2014;69:403-6.

5. Probst S, Cech C, Haentschel D, Scholz M, Ender J. A specialized post anaesthetic care unit improves fast-track management in cardiac surgery: a prospective randomized trial. Crit Care (London). 2014;18: 468.

6. Wensing M, Grol R. Knowledge translation in health: how implementation science could contribute more. BMC Med. 2019;17:88. 